\title{
A telerreabilitação como ferramenta terapêutica no protocolo de treinamento respiratório para portadores do vírus linfotrópico humano tipo I
}

\author{
Telerehabilitation as a therapeutic tool in a respiratory training protocol for human \\ lymphotropic virus type I
}
La telerehabilitación como herramienta terapéutica en un protocolo de entrenamiento respiratorio para el virus linfotropico humano tipo I

Antônio Gabriel Pantoja Silva Santos ${ }^{1}$, Rayana Carvalho Barros ${ }^{1}$, Elivelton da Costa Fonseca ${ }^{1}$, Júlio César Veiga Pena ${ }^{1}$, Amanda Caroline Lobato Dias ${ }^{1}$, Kayonne Campos Bittencourt ${ }^{1}$, Ápio Ricardo Nazareth Dias ${ }^{1}$, Danilo Marques Ferreira Normandoํ, Valéria Marques Ferreira Normando ${ }^{1 *}$.

\section{RESUMO}

Objetivo: Avaliar a resultante da supervisão fisioterapêutica indireta diante do treino aeróbico e muscular inspiratório, na força muscular inspiratória, capacidade cardiopulmonar e funcional em portadores do vírus linfotrópico $\mathrm{T}$ tipo 1 humano. Métodos: Estudo prospectivo, quantitativo e de centro único. O protocolo consistiu na associação do treino aeróbico (30'), por meio do cicloergômetro, com o treinamento muscular inspiratório (30'), por meio do Threshold IMT, orientados por meio de vídeo educacional para o uso domiciliar por 5 semanas. Um encontro semanal presencial ocorria para realizar a manovacuometria, Teste de Caminhada de Seis Minutos e o ajuste da carga do Threshold. Resultados: A amostra foi constituída por 6 voluntários, com uma média de idade de $53.57 \pm 5.12$ anos. A análise comparativa entre as medidas não resultou em significância estatística ( $p>0.05)$, porém houve evolução nos testes supracitados. Conclusão: $A$ resultante da supervisão fisioterapêutica indireta diante do treino aeróbico e muscular inspiratório evidenciou uma tendência de ganho dos parâmetros na força muscular inspiratória, capacidade cardiopulmonar e funcional.

Palavras-chave: Vírus linfotrópico T tipo 1 humano, Exercícios respiratórios, Telerreabilitação.

\begin{abstract}
Objective: To evaluate the result of indirect physical therapy supervision in the face of aerobic and inspiratory muscle training, on inspiratory muscle strength, cardiopulmonary and functional capacity in patients with human type 1 lymphotropic virus T. Methods: A prospective, quantitative, single-center study. The protocol consisted of the association of aerobic training (30'), through the cycle ergometer, with inspiratory muscle training (30'), through the Threshold IMT, guided by a home use educational video for 5 weeks. One weekly presential meeting was held to perform manovacuometry, Six-Minute Walk Test and Threshold load adjustment. Results: The sample consisted of 6 volunteers, with a mean age of $53.57 \pm 5.12$ years. The comparative analysis between the values were not significant $(p>0.05)$, although the results showed an evolution in the aforementioned tests. Conclusion: The result of indirect physiotherapeutic supervision in the face of aerobic and inspiratory muscle training showed a tendency to gain parameters in inspiratory muscle strength, cardiopulmonary and functional capacity.
\end{abstract}

Keywords: Human T-lymphotropic virus 1, Breathing exercises, Telerehabilitation.

${ }^{1}$ Universidade do Estado do Pará (UEPA), Belém - PA. *E-mail: valeriafisio@gmail.com

SUBMETIDO EM: 8/2021

ACEITO EM: 9/2021

PUBLICADO EM: 10/2021 


\section{RESUMEN}

Objetivo: Evaluar el resultado de la supervisión indirecta de fisioterapia ante el entrenamiento de los músculos aeróbicos e inspiratorios, sobre la fuerza de los músculos inspiratorios, la capacidad cardiopulmonar y funcional en pacientes con virus linfotrópico humano tipo $1 \mathrm{~T}$. Métodos: Se trata de un estudio prospectivo, cuantitativo, unicéntrico. El protocolo consistió en la asociación del entrenamiento aeróbico (30 '), a través del cicloergómetro, con el entrenamiento de la musculatura inspiratoria (30'), a través del Threshold IMT, guiado por un video educativo para uso en casa durante 5 semanas. Una reunión presencial semanal para realizar manovacuometría, prueba de marcha de seis minutos y ajuste de carga umbral. Resultados: La muestra estuvo formada por 6 voluntarios, con una edad media de 53,57 $\pm 5,12$ años. El análisis comparativo entre las medidas no resultó en significación estadística ( $p>0.05)$, sin embargo ha habido la evolución en las pruebas mencionadas. Conclusión: El resultado de la supervisión fisioterapéutica indirecta ante el entrenamiento de la musculatura aeróbica e inspiratoria mostró una tendencia a ganar parámetros en la fuerza de la musculatura inspiratoria, capacidad cardiopulmonar y funcional.

Palabras clave: Virus linfotrópico T tipo 1 humano, Ejercicios respiratorios, Telerrehabilitación.

\section{INTRODUÇÃO}

Hodiernamente, é indubitável que, o exacerbado número de tecnologias de comunicação aliado ao baixo custo de acesso à internet, possibilitaram o surgimento de vários serviços de saúde alicerçados nos recursos tecnológicos para atender pacientes tanto no âmbito hospitalar quanto no domicílio, essa abordagem terapêutica ficou conhecida como telemedicina. Assim, a telemedicina cresceu e ganhou ramos, entre eles a telerreabilitação, a qual consiste em diversas formas de reabilitação por meio do auxílio das tecnologias de telecomunicação. Portanto, a telerreabilitação pode abranger intervenções de fisioterapia, fonoaudiologia, terapia ocupacional, dentre outros (AGOSTINI M, et al., 2015).

Igualmente, Turolla A, et al. (2020) realizou um trabalho focado na telerreabilitação durante a pandemia da COVID-19, uma vez que a Organização Mundial da Saúde (OMS) orientou para o distanciamento social visando a redução da COVID-19. Desta forma, a telerreabilitação se mostrou um modelo promissor e oportuno de atendimento a ser adotado.

Em 1980, em portadores do linfoma cutâneo de células T, o HTLV-1 foi relatado pela primeira vez; no ano seguinte, o HTLV-1 também foi encontrado no Colômbia. As regiões endêmicas de infecção do HTLV-1 se localizam no sudeste do Japão, América do Sul, Oriente Médio, África Subsaariana e Caribe, as quais concentram aproximadamente de 5 a 10 milhões de indivíduos infectados pelo HTLV-1, porém, este número pode ser ainda maior em detrimento do número ínfimo de estudos acerca da prevalência do HTLV-1 (ENRÍQUEZ-RUANO B, et al., 2019; MARTINEZ MP, et al., 2019).

Ademais, entre os países da América do Sul, o Brasil é uma grande área endêmica, porém, a incidência do HTLV-1 não é uniforme no país, variando ao longo de todo território nacional. Ainda, estima-se que a região Norte e Nordeste sejam as mais afetadas, onde no Estado da Bahia, por exemplo, foi relatado recentemente que o HTLV-1 já infectou pelo menos 130.000 indivíduos, estando presente em todo 0 território do Estado (PEREIRA FM, et al., 2020).

Outrossim, o HTLV-1 é um retrovírus com um mecanismo de ação complexo e capaz de causar infecção ao longo de toda vida. Assim, o HTLV-1 afeta, sobretudo, o sistema imunológico do hospedeiro, atuando especialmente sobre os linfócitos T e células mieloides. Assim, após o HTLV-1 integrar o seu ácido ribonucléico ao ácido desoxirribonucléico (DNA) das células $\mathrm{T}$, o organismo pode ser afetado de duas maneiras: por meio da indução de anogenes que resultam em leucemia/linfoma de células $T$ em aproximadamente $5 \%$ dos pacientes ou por meio de uma reação inflamatória que ocasiona mielopatia associada ao HTLV (MAH) em 1\% dos infectados (ENRÍQUEZ-RUANO B, et al., 2019; HIRONS A, et al., 2020). 
Desta forma, em detrimento das principais alterações dos retrovírus, a capacidade funcional dos indivíduos que convivem com o HTLV pode também ser prejudicada. Esse fato mostrou-se verdadeiro nos estudos de Corrêa VAC, et al. (2018), uma vez que 50\% dos pacientes analisados revelou um nível de incapacidade moderado à grave com a presença da dificuldade de deambular, alterações na postura, no equilíbrio e a necessidade, por parte de alguns, de assistência familiar, muletas e cadeira de rodas. Além disso, dores, fadiga muscular e enfraquecimento de músculos respiratórios representam alterações físicas potencialmente prejudiciais ao desempenho de atividades tanto cotidianas, quanto laborais e complementam o quadro patológico de muitos pacientes portadores do vírus, sendo esse último sintoma diretamente relacionado a um processo miopático, tal como uma doença neuromuscular (SANTOS CMFD, 2018; LIMA GL, et al., 2016).

Da mesma forma, a literatura destaca a relação especial do HTLV-1 com alterações respiratórias, haja visto que pneumonias, tuberculose, bronquiolite, entre outras anormalidades pulmonares são relatadas nesses pacientes (DIAS A, et al., 2018). Ainda, no estudo de Falcão LFM, et al. (2017) foi destacado que os indivíduos com HTLV-1 apresentavam alteração da função pulmonar quando comparados com os indivíduos saudáveis, as principais alterações encontradas foram a redução da Capacidade Vital (CV) e do Volume Expiratório Forçado no Primeiro Segundo (VEF1).

Diante disso, a fisioterapia mostra-se competente a prática assistencial em pacientes portadores do HTLV-1, atuando na prevenção e no tratamento de inúmeras complicações, a exemplo da degradação pulmonar, fraqueza muscular e dispneia, uma vez que os indivíduos sofrem infecção viral de suas células imunes, gerando resposta inflamatória exagerada e manifestações clínicas passíveis de intervenções (MOREIRA WEM, CASSIMIRO MS, 2020; OLIVEIRA TSS, et al., 2019).

Assim, em relação ao tratamento fisioterapêutico propriamente dito, a literatura relata que as condições relacionadas com a difícil locomoção, ausência de transporte e precariedades financeiras foram alguns dos principais problemas enfrentados por pacientes para manter seus tratamentos ambulatoriais (BITTAR OJNV, et al., 2016).

Além disso, é insofismável que a pandemia da COVID-19 constituiu um fator de agravo ao problema supracitado, prejudicando de forma significativa os tratamentos no âmbito ambulatorial, haja vista que, com o objetivo de reduzir a transmissão do Sars-CoV-2 e, por conseguinte, mitigar as chances de um possível colapso dos sistemas nacionais de saúde. Os profissionais de saúde, incluindo os fisioterapeutas, interromperam os seus atendimentos ambulatoriais considerados não urgentes. Porém, apesar dessa atitude evidenciar a responsabilidade social dos fisioterapeutas, destaca-se também dois possíveis problemas importantes, a convivência dos pacientes com as limitações funcionais e a prática limitada destes profissionais de saúde durante a referida pandemia (TUROLLA A, et al., 2020).

Igualmente, é indubitável que há uma grande carência na literária acerca dos tratamentos domiciliares, apesar de alguns aspectos benéficos geralmente serem enfatizados, tal como autonomia do paciente, o conforto de estar no próprio lar, autoconfiança e manutenção da família como ambiente terapêutico, é inquestionável a necessidade de mais trabalhos científicos que utilizem a estratégia terapêutica supracitada (SILVA KL, et al., 2017). Portanto, o objetivo do presente estudo foi avaliar a associação do treino aeróbico e muscular inspiratório, na força muscular inspiratória, capacidade cardiopulmonar e funcional, sob supervisão fisioterapêutica indireta, em portadores do HTLV-1.

\section{MÉTODOS}

O presente estudo trata-se de um ensaio clínico, longitudinal, prospectivo, quantitativo e de centro único, realizado após aprovação do Comitê de Ética em Pesquisa (CEP) da Universidade do Estado do Pará (UEPA) e após aceitação dos voluntários, por meio do Termo de Consentimento Livre e Esclarecido (TCLE).

Este estudo teve como sede de triagem e avaliações semanais, o laboratório do Grupo de Estudo Desenvolvimento e Reabilitação na Amazônia (GEDERAM) localizado na Unidade de Ensino e Assistência em Fisioterapia e Terapia Ocupacional (UEAFTO). 
A rotina protocolar foi realizada em domicílio, sob supervisão fisioterapêutica indireta, fazendo monitoração via contato telefônico. Enaltecendo que para as atividades referentes ao treinamento muscular inspiratório e aeróbico utilizaram um vídeo educacional para orientação domiciliar.

Ademais, foram utilizados como referência o universo amostral do trabalho intitulado "Estudo da eletromiografia de superfície no decurso do Treinamento Muscular Respiratório domiciliar em portadores do Vírus Linfotrópico Humano Tipo 1" (DIAS A, et al., 2018), integralizando, o exercício aeróbico com cicloergômetro para a análise da capacidade cardiopulmonar e funcional, além da reavaliação da força muscular respiratória.

Adotou-se como critério de inclusão, voluntários de ambos os sexos, com idade igual ou superior a 40 anos, portadores de sorologia positiva para HTLV-1 com PET/MAH definitivo ou provável. E para exclusão, doenças pulmonares, comorbidades graves tais com (cardiopatia e hipertensão arterial não controlada; alterações cognitivas que impedissem a condução do protocolo.

Os voluntários passaram pela avaliação fisioterapêutica inicial e reavaliação final, sendo este objeto de referência de triagem do GEDERAM aos portadores do vírus HTLV-1 encaminhados a reabilitação.

A avaliação da força muscular respiratória foi realizada semanalmente por meio da aferição das medidas de pressão inspiratória (PImáx) e expiratórias máximas (PEmáx) utilizando o manovacuômetro digital da GlobalMed TM (+- 300CMH20 - Porto Alegre - RS - Brasil).

Para realizar a mensuração da PImáx e da PEmáx, os voluntários foram posicionados sentados a urna cadeira com encosto e o manovacuômetro foi colocado na posição intraoral por meio de um bocal com a vedação da cavidade nasal por meio de um clipe. Para a mensuração da PImáx solicitou-se um esforço inspiratório até a capacidade pulmonar total (CPT), a partir do volume residual (VR), para o registro da medida. A PEmáx foi aferida solicitando-se o esforço expiratório, a partir da CPT, após inspiração máxima, até o VR, para o registro da medida.

As técnicas de mensuração foram repetidas até completarem 3 (três) medidas satisfatórias, tanto da PImáx quanto da PEmáx, com variação de até 10\% entre estas, e intervalo de repouso entre cada esforço respiratório foi de 1 minuto. O valor de PImáx e PEmáx considerado para o estudo foi aquele valor máximo obtido dentre a três manobras. Os indivíduos foram constantemente instruídos a realizar esforço máximo de maneira adequada.

Ressalta-se que os avaliadores fizeram uso de máscara facial descartável e luva de procedimento a fim de garantir a proteção de contato com o paciente. As peças do manovacuômetro foram esterilizadas a cada uso com a imersão por 30 minutos em hipoclorito de sódio a $0,4 \%$ e os bocais descartados a cada uso.

Para avaliação da capacidade funcional dos voluntários, foi utilizado o Teste de Caminhada de Seis Minutos (TC6), o qual propõe avaliar a resposta funcional dos sistemas envolvidos durante exercício, inclusive nas variáveis cardiovascular e pulmonar. O teste foi aplicado semanalmente nos encontros presenciais com o objetivo de analisar a distância percorrida e avaliar sua correlação com o protocolo. Para tal utilizou-se um corredor de 30 metros com superfície plana e antiderrapante. Antes e após o TC6 foi verificada a saturação periférica de oxigênio $\left(\mathrm{SPO}_{2}\right)$ e frequência cardíaca: $(\mathrm{FC})$ por oximetria de pulso, além do resultado na escala de Borg para dispneia.

Os voluntários do estudo foram orientados quanto ao complemento terapêutico por meio do treinamento muscular inspiratório (TMI) realizado no turno matutino, por 30 minutos por 5 semanas. Eles receberam o dispositivo de carga linear Threshold® IMT e as orientações devidas quanto a manuseio, postura e assepsia. A carga de treinamento inicial para cada voluntário foi ajustada em $25 \%$ da Plmáx. Os mesmos foram treinados e instruídos a fazer o programa de exercícios por conta própria no seu domicílio. Uma vez por semana, durante a volta ao laboratório, o pesquisador determinou novos valores para carga (1a. semana $25 \%$; 2a. semana $35 \%$; 3a. semana $40 \%$; 4 a. semana $45 \%$; 5 a. semana, $50 \%$ ). O dispositivo foi lacrado para que os voluntários não tivessem acesso a mudança na carga de treinamento. Outrossim, após o TMI, o voluntário realizava o treino aeróbico de 30 minutos no cicloergômetro (WCT Fitness 60820) para MMII, fazendo o devido registro da distância percorrida oferecida pelo acelerômetro. 
A primeira sessão de treinamento de cada semana foi realizada no GEDERAN sob supervisão direta do pesquisador e as outras sessões de treinamento em domicílio sob supervisão a distância do pesquisador, fazendo uso do vídeo educacional para os referidos treinamentos muscular inspiratório e aeróbico.

\section{RESULTADOS}

No total, foram recrutados 10 indivíduos portadores de HTLV-1, sendo 4 excluídos por descontinuidade ao protocolo. Seis voluntários, 4 do sexo masculino e 2 do sexo feminino, com a média de idade de $53.57 \pm$ 5.12. A caracterização de dados sociodemográficos dos participantes da pesquisa é apresentada na tabela 1.

Tabela 1- Características dos participantes da pesquisa.

\begin{tabular}{ll}
\hline Variáveis & Resultados \\
\hline Idade & $53.57 \pm 5.12$ \\
\hline Sexo & 2 \\
\hline Feminino & 4 \\
Masculino & 0 \\
\hline Tabagista & 6 \\
\hline Sim & \\
Não & 3 \\
\hline Etilista & 3 \\
\hline Sim & \\
Não & 4 \\
\hline Dieta Alimentar & 2 \\
\hline Sim & \\
Não & 4 \\
\hline Atividade Física & 2 \\
\hline Pratica & \\
Não & 3 \\
\hline Distúrbio do sono & 3 \\
\hline Possui & \\
Não possui & 4 \\
\hline Perda de Urina & 2 \\
\hline Sim & \\
Não & 1 \\
\hline Doenças Crônicas não Transmissíveis & 5 \\
\hline Sim & \\
Não & 1 \\
\hline Reposição Hormonal & 5 \\
\hline Sim & \\
Não & \\
\hline Menopausa & \\
\hline Sim & \\
Não & \\
Não se aplica & \\
\hline Fonte: Santos AGPS, & \\
\hline
\end{tabular}

Fonte: Santos AGPS, et al., 2021.

Em relação aos testes e exames realizados durante as cinco semanas de protocolo de exercícios, os dados são apresentados abaixo, sendo que, apesar de não ter apresentado diferença estatisticamente significativa entre a T0 (avaliação inicial) e a T35 ( $35^{\circ}$ dia de treinamento), em todas as variáveis analisadas houve aumento da média (Tabela 2). 
Tabela 2 - Valores obtidos referentes ao TC6, Manovacuometria, cicloergômetro e espirometria, apresentados em média e desvio padrão.

\begin{tabular}{lccc}
\hline Variáveis & T0 $(\mathbf{n}=6)$ & T35 $(\mathbf{n}=6)$ & P valor \\
\hline TC6 & & & \\
\hline Metros & $275 \pm 168.01$ & $300 \pm 168.76$ & 0.2807 \\
\hline Manovacuometria & & & \\
\hline PImáx & $-80.16 \pm 14.74$ & $-96.33 \pm 14.63$ & 0.1259 \\
PEmáx & $90.50 \pm 19.35$ & $93.66 \pm 21.24$ & 0.7463 \\
\hline Cicloergômetro & & \\
\hline Número de Ciclos & & \\
\hline Espirometria & $1136.80 \pm 631.91$ & $1239.00 \pm 457.42$ & 0.9060 \\
\hline CVF (L) & & \\
VEF1 (L) & $2.66 \pm 0.51$ & $2.83 \pm 0.75$ & 0.3173 \\
VEF1/CVF (\%) & $2.70 \pm 0.31$ & $2.16 \pm 0.40$ & 0.3173 \\
TFEF (segundos) & $81.16 \pm 3.76$ & $81.00 \pm 5.93$ & 0.9128 \\
FEF25-75\% (L/s) & $5.83 \pm 1.60$ & $6.33 \pm 1.75$ & 0.5416 \\
\hline
\end{tabular}

Legenda: $\mathrm{n}$ : tamanho da amostra, Teste de Caminhada de 6 Minutos (TC6), Capacidade Vital Forçada (CVF), Volume Expiratório Forçado no Primeiro Segundo (VEF1), Relação VEF1 / CVF, Tempo de Fluxo Expiratório Forçado (TFEF), Fluxo Expiratório Forçado Médio (FEF 25-75\%).

Fonte: Santos AGPS, et al., 2021.

\section{DISCUSSÃO}

Até o presente momento, são poucos os estudos que abordam os efeitos de um treinamento muscular inspiratório associado ao aeróbico, sob supervisão fisioterapêutica indireta, em uma população portadora do Vírus Linfotrópico Humano Tipo I - HTLV-1.

No presente estudo, foi observado que $33,33 \%$ dos participantes se utilizavam de bengala ou andador para realizarem suas atividades de vida diária. Isso pode ser justificado pelo fato de o HTLV-1 interagir com o corpo humano, manifestando alterações clínicas em vários segmentos, pele, pulmão, articulações, entre outros, inclusive frequentemente de forma intermediária, antes de ocorrer a mielopatia associada ao HTLV-1 (HAM), condição em que a regressão da força muscular nos membros inferiores propicia distúrbios de marcha e, a longo prazo, a necessidade do uso de auxílios para locomoção (ROSADAS C, et al., 2021).

No estudo de Marconi CSC, et al. (2021), entre as diversas variáveis dos pacientes portadores de HTLV1 analisadas, a funcionalidade foi uma das que se mais destacaram, haja vista que, apesar da primeira infecção retroviral a humanos ter sido causado pelo HTLV-1, estes pacientes nos dias atuais ainda apresentam um grande declínio de funcionalidade quando comparado as infecções causadas pelo vírus da imunodeficiência humana (HIV). Assim, o resultado do estudo supracitado converge com o presente estudo, uma vez que, apesar de ter ocorrido aumento na distância percorrida durante o TC6 após o término do protocolo de atendimento, esta diferença não foi estatisticamente significativa.

Além disso, as alterações neurológicas podem ter sido uns dos fatores que podem ter contribuído para impedir uma melhora maior da funcionalidade após o estudo. Sabe-se que o HTLV-1 está intrinsicamente relacionado à inflamação muscular; ainda, mesmo que outras mudanças e alterações no cérebro não estejam presentes, a miopatia pode afetar estes pacientes de forma independente, prejudicando, por exemplo, a capacidade dos músculos de extrair e utilizar o oxigênio durante as atividades de vida diária, reverberando, assim, em danos dantescos à funcionalidade dos pacientes com HTLV-1 (DESDOUITS M, et al., 2013; RASO V, et al., 2013; GOMES-NETO M, et al., 2018).

Todavia, apesar das possíveis alterações citadas, houve melhora da média da funcionalidade após o estudo, indicando tendência de melhora desta variável por meio da supervisão fisioterapêutica indireta diante do treino aeróbico e muscular inspiratório. Portanto, a melhora na distância percorrida pode estar relacionada com o treinamento aeróbico, reconhecido como uma modalidade de exercício capaz de melhorar a capacidade pulmonar, a qual interfere diretamente na performance muscular (SHEIKH AM e 
VISSING J, 2019). Portanto, a utilização do cicloergômetro em um programa de reabilitação, pode ser capaz de melhorar parâmetros aeróbicos, aumentando a resistência à fadiga. No presente estudo, observou-se aumento da quantidade em número de ciclos realizados no cicloergômetro quando se comparou o $35^{\circ}$ dia de protocolo com a avaliação inicial, embora não tenha representado uma diferença significativa.

O processo inflamatório causado pela resposta imune exacerbada ao vírus é evidenciado por cascatas hiperinflamatórias, pelo recrutamento de citocinas, que acometem maleficamente os pulmões, tendo a dispneia e a tosse crônica como sinais físicos percebidos mais comumente (CACHAY R, et al., 2021). Com isso, a força muscular respiratória se mostra alterada em $100 \%$ dos participantes no presente estudo, com valores de pressão inspiratória e expiratória obtidos no teste de manovacuometria abaixo do esperado, segundo Oliveira JJJD, et al. (2016).

A influência do HTLV-1 no comprometimento funcional da capacidade respiratória, é causada principalmente por infecções oportunistas ou infiltração pulmonar de células leucêmicas para os pacientes com Leucemia/Linfoma de Células $T$ do Adulto e em portadores assintomáticos, já em pacientes com PET/MAH podem ser observados alveolíte $\mathrm{T}$ linfocítica, pneumonia interesticial, bronquiolite $\mathrm{e}$ panbronquiolite difusa, além do risco aumentado para cryptococcose pulmonar, tuberculose pulmonar e pneumonia adquirida na comunidade (FUKUOKA J, et al., 2013; ATSUMI E, et al., 2009). Desta forma, no que concerne a avaliação da força muscular inspiratória e expiratória analisados neste estudo, registrou tendência positiva ao ganho de força por aumento das médias para ambos, sem significância estatística. Dessa forma é essencial que o tratamento de tal patologia seja embasado na manutenção da estabilidade clínica e na participação de programas de reabilitação pulmonar, visando uma redução da percepção da dispneia aos esforços e consequente manutenção da qualidade de vida desses pacientes.

Outrossim, estudos a respeito da função pulmonar em pacientes com HTLV-1 são escassos. No presente estudo foi possível analisar que não houve diferença significativa na influência do protocolo de tratamento na análise da espirometria, na qual a Relação do Tempo de Fluxo Expiratório Forçado (TFEF) se manteve dentro do padrão de normalidade, sendo superior a $80 \%$ e na Capacidade Vital Forçada (CVF), a no Volume Expiratório Forçado no Primeiro Segundo (VEF1), que se manteve dentro do padrão de normalidade.

No estudo conduzido por Matsuyama W, et al. (2003) foram descritas reduções significativas de CV e VEF1 nos pacientes com HTLV-1 comparados a indivíduos sadios, e os autores associaram tais alterações funcionais às áreas de lesões pulmonares observadas no primeiro grupo. Desse modo, é válido ressaltar que no presente estudo não houve estagnação dos valores, mas sim aumento deles. Isso pode ser compreendido pelo protocolo de 35 dias.

No contexto da pandemia, o acompanhamento terapêutico indireto se tornou uma realidade ainda mais viável, a fim de minimizar os riscos de contaminação durante a pandemia e promover uma prestação de cuidados em saúde. Dessa maneira, a telerreabilitação pode ser considerada uma ferramenta capaz de estabelecer, de forma direta, o acompanhamento contínuo bem como a realização do plano terapêutico, além de proporcionar um canal para sanar dúvidas dos pacientes acerca dos protocolos realizados em domicílio (TUROLLA A, et al., 2020). Desse modo, no presente estudo tornou-se evidente os efeitos positivos da telerreabilitação dos pacientes portadores do HTLV-1, ao modo que houve um acompanhamento constante dos pacientes durante a pandemia da COVID-19, e ao término do protocolo foi evidenciado tendência de melhora em todas as variáveis estudadas.

Assim, tais resultados positivos do presente protocolo de telerreabilitação também vão ao encontro com outros estudos utilizando a telerreabilitação durante a pandemia da COVID-19, como o trabalho de Gonzalez-gerez JJ, et al. (2020) que constatou benefícios do ponto de vista muscular e respiratório, além de evitar a inatividade e suas complicações, como descompensações metabólicas e nutricionais.

O estudo aponta limitações quanto ao tamanho amostral. Ainda assim, destaca-se a influência da pandemia da COVID-19 como precursor a baixa adesão de voluntários ao estudo pelo risco ao Sars-cov2. Os autores preveem a continuidade deste estudo, com tamanho amostral maior e com protocolos superiores a 5 semanas com os pacientes portadores do HTLV-1. 


\section{CONCLUSÃO}

O treinamento muscular inspiratório associado ao aeróbico, sob supervisão fisioterapêutica indireta, em portadores do HTLV-1, revelou ser capaz de otimizar a força muscular inspiratória, capacidade cardiopulmonar e funcional, sob auxílio das tecnologias de telecomunicações. Porém, em detrimento do tamanho amostral e ao tempo de aplicação do estudo, as análises das variáveis do estudo foram limitadas, não sendo estatisticamente significativas. Tais resultados evidenciam a necessidade de uma maior atenção sobre os protocolos de telerreabilitação, visando, assim, otimizar possíveis benefícios deste ramo da telemedicina, sobretudo no atual cenário de pandemia.

\section{REFERÊNCIAS}

1. AGOSTINI M, et al. Telerehabilitation and recovery of motor function: a systematic review and meta-analysis. Journal of telemedicine and telecare, 2015; 21(4): 202-213.

2. ATSUMI E, et al. Influence of human T lymphotropic virus type I infection on the etiology of community-acquired pneumonia. Internal Medicine, 2009; 48(12): 959-965.

3. BITTAR OJNV, et al. Absenteísmo em atendimento ambulatorial de especialidades no estado de São Paulo. BEPA, 2016; (13)152: 19-32.

4. CACHAY R, et al. Clinical, Radiological and Functional Characteristics of Pulmonary Diseases among HTLV-1 Infected Patients without Prior Active Tuberculosis Infection. Pathogens, 2021; 10(7): 895.

5. CORREA VAC, et al. Capacidade funcional em indivíduos com paraparesia espástica tropical/mielopatia associada ao HTLV-1. Revista Família, Ciclos de Vida e Saúde no Contexto Social, 2018; 6(1): 7-14.

6. DESDOUITS M, et al. HTLV-1-associated inflammatory myopathies: low proviral load and moderate inflammation in 13 patients from West Indies and West Africa. J Clin Virol, 2013; 57: 70-76.

7. DIAS A, et al. Human T lymphotropic virus and pulmonary diseases. Frontiers in microbiology, 2018; 9, 1879.

8. ENRÍQUEZ-RUANO $P$, et al. Myelopathy secondary to human T-lymphotropic virus and Treponema pallidum infection: case report. Spinal cord series and cases, 2019; 5(1): 1-5.

9. FUKUOKA J, et al. Lung miliary micro-nodules in human T-cell leukemia virus type I carriers. Pathology international, 2013; 63(2): 108-112.

10. FALCÃO LFM, et al. CT Chest and pulmonary functional changes in patients with HTLV-associated myelopathy in the Eastern Brazilian Amazon. PLoS One, 2017; 12(11): e0186055.

11. GOMES-NETO M, et al. Muscle Strength and Aerobic Capacity in HIV-Infected Patients: A Systematic Review and Meta-Analysis. J Acquir Immune Defic Syndr, 2018; 79(4): 491-500.

12. GONZALEZ-GEREZ JJ, et al. Therapeutic pulmonary telerehabilitation protocol for patients affected by COVID-19, confined to their homes: study protocol for a randomized controlled trial. Trials, 2020; 21(1): 1-9.

13. HIRONS A, et al. Human T-cell lymphotropic virus type-1: a lifelong persistent infection, yet never truly silent. The Lancet Infectious Diseases, 2020.

14. LIMA GL, et al. Fisioterapia respiratória na paraparesia espástica tropical decorrente do HLTV. Revista científica dos profissionais de fisioterapia, 2016; 117.

15. MARTINEZ MP, et al. Virologia comparativa de HTLV-1 e HTLV-2. Retrovirology, 2019; 16 (1): 1-12.

16. MORALES-BLANHIR JE, et al. Teste de caminhada de seis minutos: uma ferramenta valiosa na avaliação do comprometimento pulmonar. Jornal Brasileiro de Pneumologia, 2011; 37, 110-117.

17. MARCONI CSC, et al. Comparison of functioning and health-related quality of life among patients with HTLV-1, HIV, and HIV-HTLV-1-coinfection. Revista da Sociedade Brasileira de Medicina Tropical, 2021; 54.

18. MOREIRA WEM, CASSIMIRO MS. O papel do fisioterapeuta respiratório na abordagem do paciente com insuficiência respiratória: realidades da assistência domiciliar. Revista Saúde e Desenvolvimento, 2020; (13)15.

19. MATSUYAMA W, et al. Influence of human T Iymphotrophic virus type I on cryptogenic fibrosing alveolitis - HTLV-I associated fibrosing alveolitis: proposal of a new clinical entity. Clin. Exp. Immunol, 2003; 133(3): 397-403.

20. OLIVEIRA TSS, et al. Prevalência de sintomas intestinais em pacientes infectados com vírus T-linfotrópico humano tipo 1. Rev Soc Bras Med, 2019; 52, e20180486.

21. OLIVEIRA JJJD, et al. Efeito da fisioterapia ambulatorial pós-operatória sobre a capacidade funcional e a força muscular respiratória em pacientes submetidos à cirurgia bariátrica. ABCD. Arquivos Brasileiros de Cirurgia Digestiva, 2016; 29: 43-47.

22. PEREIRA FM, et al. Distribution of Human T-Lymphotropic Virus (HTLV) and Hepatitis C Co-infection in Bahia, Brazil. PloS one, 2020; 15(7): e0223087.

23. RASO V, et al. Association between muscle strength and the cardiopulmonary status of individuals living with HIV/AIDS. Clinics, 2013; 68: 359-364.

24. ROSADAS C, et al. Protocolo Brasileiro para Infecções Sexualmente Transmissíveis 2020: infecção pelo vírus linfotrópico de células T humanas (HTLV). Epidemiologia e Serviços de Saúde, 2021; 30.

25. SANTOS CMFD. Relação entre a qualidade de vida no trabalho e a infecção pelo HTLV-1. Tese (Doutorado em medicina e saúde pública) - Escola Bahiana de Medicina e Saúde Pública, Salvador - BA, 2018; 137 p.

26. SILVA KL. Por que é melhor em casa? A percepção de usuários e cuidadores da atenção domiciliar. Cogitare Enfermagem, 2017; 22(4).

27. SHEIKH AM e VISSING J. Terapia de exercício para doenças musculares e do neurônio motor inferior. Acta Myologica, 2019; 38 (4): 215.

28. TUROLLA A, et al. Musculoskeletal physical therapy during the COVID-19 pandemic: is telerehabilitation the answer?. Physical therapy, 2020; 100(8): 1260-1264. 